\title{
A Pharmacoeconomic Model Comparing Two Long-Acting Treatments for Overactive Bladder
}

\author{
LES NOE, MPA; RUSSELL BECKER, MA; TODD WILLIAMSON, PhD; and DONNY CHEN, AB
}

\begin{abstract}
OBJECTIVE: To compare the estimated first-line treatment costs of extended-release tolterodine versus controlled-release oxybutynin in patients with overactive bladder (OAB).

METHODS: We developed a decision-analysis model to estimate the patterns of treatment, resource consumption, and cost impact of treating $\mathrm{OAB}$ with either controlledrelease oxybutynin or extended-release tolterodine as first-line drug therapy. We used data from the published literature to develop the framework for the model and supplemented this information with expert opinion, where necessary. Based on recent clinical studies, we assumed equal efficacy between the comparators and reduced the model to a cost-minimization analysis. The model was constructed from the payer perspective, and all costs are given in 2000 U.S. dollars.
\end{abstract}

RESULTS: A base-case analysis was generated showing that patients initiating therapy with extended-release tolterodine have probable average 3-month treatment costs of $\$ 1,207$ compared to $\$ 1,283$ for patients initiating with controlled-release oxybutynin, for a $6.3 \%$ difference. First-line $O A B$ direct drug costs account for $19 \%$ and $15 \%$ of total costs for extended-release tolterodine and controlled-release oxybutynin, respectively. Sensitivity analysis showed these results to be relatively stable.

CONCLUSION: The results from this analysis suggest that for patients with OAB and initiating long-acting pharmacologic therapy in the primary care setting, the treatment with extended-release tolterodine is slightly less costly than treatment with controlledrelease oxybutynin. Studies directly comparing these treatment alternatives are needed, however, to determine which approach or combination of approaches is the most cost-effective.

KEYWORDS: Overactive bladder, OAB, Decision-analysis model, Oxybutynin, Tolterodine, Cost minimization

J Managed Care Pharm. 2002(8)5:343-52

\section{Authors}

LES NOE, MPA, is Vice President of Scientific Affairs, RUSSELL BECKER, MA is Senior Manager, and DONNY CHEN, AB, is Senior Data Analyst, Ovation Research Group, Highland Park, Illinois; TODD WILLIAMSON, PhD, is Senior Director, Global Health Outcomes, Pharmacia Corporation, Peapack, New Jersey.

AUTHOR CORRESPONDENCE: Russell Becker, Senior Manager, Ovation Research Group, 600 Central Ave., Suite 265, Highland Park, IL 60035. E-mail: rbecker@ovation.org

Copyright $\odot$ 2002, Academy of Managed Care Pharmacy. All rights reserved.
7 he cost of overactive bladder $(\mathrm{OAB})$ is a significant financial burden on patients, families, and the health care system. In 2000, the total economic cost of OAB in the United States was estimated at $\$ 18.2$ billion, which is more than either osteoporosis or Parkinson's disease. OAB costs at the community level were approximately $\$ 13.8$ billion, while costs at institutions were $\$ 4.4$ billion. ${ }^{1}$ A study examining insurance claims showed that total annual claims among $\mathrm{OAB}$ patients was $\$ 5,018$ versus $\$ 1,767$ among non-OAB controls (1995 dollars). ${ }^{2}$

\section{Drug Treatment for OAB}

Head-to-head studies comparing 2 immediate-release forms of antimuscarinic drug therapy, oxybutynin, and tolterodine, have shown that they have similar efficacy; however, tolterodine has an improved side-effect profile, most notably less dry mouth, and is associated with fewer treatment withdrawals as a result of drug-related adverse events. ${ }^{3-7}$

The side effects from $\mathrm{OAB}$ drug therapy have resulted in poor compliance and, subsequently, low persistence with therapy over time. ${ }^{4,8,9}$ Persistence with drug therapy is important for achieving long-term treatment benefits. In a number of retrospective claims studies, patients receiving tolterodine have been shown to remain on therapy longer than those receiving oxybutynin. ${ }^{6,-15}$ There is also evidence that suggests that OAB patients who are able to continue with medication have greater symptom improvement and use fewer resources. ${ }^{16}$

Phase III clinical trials of controlled-release oxybutynin have indicated better patient compliance, reduced side effects, and equivalent efficacy as compared to oxybutynin IR. ${ }^{17-19}$ Both extended-release tolterodine and controlled-release oxybutynin have been shown to be more effective and better tolerated than immediate-release tolterodine. ${ }^{20,21}$ These data further suggest that extended-release tolterodine has better tolerability and fewer side effects than controlled-release oxybutynin. Although there are no head-to-head studies to suggest that one of the extended-release drugs is more efficacious than the other, one recent study compared extended-release tolterodine to controlled-release oxybutynin using a 4-way crossover design in a small number of patients. ${ }^{22}$ Using change in bladder capacity as a surrogate for efficacy, a $6 \mathrm{mg}$ dose of extended-release tolterodine was found to be equivalent to a $20 \mathrm{mg}$ dose of oxybutynin. However, the $6 \mathrm{mg}$ dose of extended-release tolterodine produced a side-effect profile with respect to dry mouth similar to the $10 \mathrm{mg}$ dose of controlled-release oxybutynin. This implies that extended-release tolterodine might be as efficacious as oxybutynin but has an improved tolerability profile. 


\begin{tabular}{|c|c|c|}
\hline Resource Variable & $\begin{array}{l}\text { CPT-4 } \\
\text { Code }\end{array}$ & $\operatorname{Cost}^{*}$ \\
\hline \multicolumn{3}{|l|}{ Drug Cost (per day) } \\
\hline $\begin{array}{l}\text { Extended-release tolterodine } 2 \mathrm{mg} \\
\text { Extended-release tolterodine } 4 \mathrm{mg} \\
\text { Controlled-release oxybutynin } 5 \mathrm{mg} \\
\text { Controlled-release oxybutynin } 10 \mathrm{mg} \\
\text { Controlled-release oxybutynin } 15 \mathrm{mg} \\
\text { Imipramine } 50 \mathrm{mg} \text { tid } \\
\text { Estrogen } 2 \mathrm{gm} \text { qod } \\
\text { Other Drugs (flavoxate, } \\
\text { dicyclomine, hyoscyamine) }\end{array}$ & $\begin{array}{l}\text { N/A } \\
\text { N/A } \\
\text { N/A } \\
\text { N/A } \\
\text { N/A } \\
\text { N/A } \\
\text { N/A } \\
\text { N/A }\end{array}$ & $\begin{array}{l}\$ 2.73 / \text { day }^{37} \\
\$ 2.80 / \text { day }^{37} \\
\$ 2.44 / \text { day }^{37} \\
\$ 2.69 / \text { day }^{37} \\
\$ 2.94 / \text { day }^{37} \\
\$ 2.07 / \text { day }^{37} \\
\$ 1.12 / \text { day }^{37} \\
\\
\$ 2.11 / \text { day }^{37}\end{array}$ \\
\hline \multicolumn{3}{|l|}{ Physician Costs } \\
\hline $\begin{array}{l}\text { Physician office visit (PCP): } \\
\text { outpatient follow-up } \\
\text { Physician office visit (PCP): } \\
\text { outpatient follow-up } \\
\text { Physician office visit (Specialist): } \\
\text { outpatient follow-up } \\
\text { Incontinence pads }\end{array}$ & $\begin{array}{c}99244 \\
\text { N/A }\end{array}$ & $\begin{array}{c}\$ 144.31 / \mathrm{visit}^{36} \\
\$ 5.17 / \mathrm{pad}^{37}\end{array}$ \\
\hline \multicolumn{3}{|l|}{ Physical and Behavioral Therapy } \\
\hline $\begin{array}{l}\text { Behavioral therapy } \\
\text { Biofeedback } \\
\text { Electrical stimulation } \\
\text { Other therapy }\end{array}$ & $\begin{array}{l}97112 \\
90911 \\
97014 \\
97139\end{array}$ & $\begin{array}{l}\$ 24.44^{36} \\
\$ 67.04^{36} \\
\$ 13.33^{36} \\
\$ 13.51^{36}\end{array}$ \\
\hline \multicolumn{3}{|l|}{ Procedures/Tests } \\
\hline $\begin{array}{l}\text { Cystoscopy } \\
\text { Cystometrogram/Pressure } \\
\text { flow urodynamics } \\
\text { Urine flowmetry } \\
\text { Urethral pressure profile } \\
\text { Cystogram (VCUG) } \\
\text { Urine cytology } \\
\text { Post-void residual } \\
\text { Urinalysis } \\
\text { Dipstick urinalysis }\end{array}$ & $\begin{array}{l}51726 \\
51741 \\
51772 \\
74430 \\
88104 \\
78730 \\
81005 \\
81000\end{array}$ & $\begin{array}{l}\$ 75.40^{36} \\
\$ 44.97^{36} \\
\$ 67.59^{36} \\
\$ 38.78^{36} \\
\$ 30.94^{36} \\
\$ 50.98^{36} \\
\$ 19.81^{36} \\
\$ 19.81^{36}\end{array}$ \\
\hline \multicolumn{3}{|l|}{$\overline{\text { Comorbid Conditions }}$} \\
\hline $\begin{array}{l}\text { Urinary tract infections } \\
\text { Skin infections } \\
\text { Depression } \\
\text { Fractures }\end{array}$ & $\begin{array}{l}\text { N/A } \\
\text { N/A } \\
\text { N/A } \\
\text { N/A }\end{array}$ & $\begin{array}{c}\$ 53.96^{31} \\
\$ 21.69^{31} \\
\$ 182.87^{36,37} \\
\$ 2,934.37^{38}\end{array}$ \\
\hline \multicolumn{3}{|l|}{ Productivity Losses } \\
\hline $\begin{array}{l}\text { Low resource group (per } 3 \text { months) } \\
\text { Medium resource group (per } 3 \text { months) } \\
\text { High resource group (per } 3 \text { months) }\end{array}$ & $\begin{array}{l}\text { N/A } \\
\text { N/A } \\
\text { N/A }\end{array}$ & $\begin{array}{c}\$ 0.00^{34} \\
\$ 293.66^{34} \\
\$ 587.31^{34}\end{array}$ \\
\hline \multicolumn{3}{|c|}{$\begin{array}{l}\text { * Medication costs are calculated using average wholesale prices (AWP). } \\
\text { Urinary tract and skin infection costs are based on claims data from } \\
\text { California's Medicaid (Medi-Cal) program. All other costs reflect actual } \\
\text { payments based on published DRG and physician fee schedules. All costs } \\
\text { were inflation-adjusted, if necessary, to reflect } 2000 \text { U.S. dollars using the } \\
\text { Bureau of Labor Statisitics CPI-U for Medical Care Services. }{ }^{39}\end{array}$} \\
\hline
\end{tabular}

Economic considerations of the treatment of OAB have been previously described. ${ }^{23-25}$ These economic analyses have focused primarily on comparing the immediate-release forms of tolterodine and oxybutynin or long-acting oxybutynin with immediate-release tolterodine. ${ }^{26,27}$ However, one recent economic analysis compared the 2 long-acting products and suggested that extended-release tolterodine might be less costly overall than controlled-release oxybutynin. ${ }^{28}$

The objective of our analysis was to develop a decisionanalysis model to compare the 3-month economic impact of treating $\mathrm{OAB}$ with extended-release tolterodine and controlledrelease oxybutynin.

\section{Methods}

This model estimates the patterns of treatment, resource consumption, and cost impact of treating $\mathrm{OAB}$ with either controlled-release oxybutynin or extended-release tolterodine as first-line drug therapy. We used data from the published literature to develop the framework for the model and supplemented this information with expert opinion, where necessary, due to a lack of published data. Expert opinions were obtained using a modified Delphi method from 4 practicing urologists who have experience in the field of overactive bladder research and treatment. They utilized their own personal knowledge and professional experience in responding to a specific set of questions regarding specific data points. Specifically, we used expert opinion to (1) estimate the percentage of patients who receive various treatments in the model and (2) confirm or modify estimates regarding drug dosing and resource consumption.

After the first round of estimates were obtained, each panel member was provided, in a blinded manner, with the estimates obtained from the other experts and given the opportunity to make adjustments, if they felt it was necessary. The results from the second round were averaged to obtain the final estimates used in the model. The ranges were used in sensitivity analyses.

This analysis was conducted from a payer perspective. All costs were obtained from published literature and standardized databases (Table 1) and are given in 2000 U.S. dollars.

\section{Treatment Comparators}

We limited our comparison to the long-acting forms of oxybutynin and tolterodine. Given that the limited number of studies including one or both of these drugs did not suggest that one treatment is more effective than the other, we assumed they were equally effective.

\section{Model Design}

Figure 1 shows a schematic of the decision-analysis model used. The model includes outpatients with a diagnosis of $\mathrm{OAB}$ seeking treatment from primary care physicians (PCPs). Patients entering the model are diagnosed as having $\mathrm{OAB}$ with an age range of 20 to 89 years (mean 60 years), matching that of key, published clinical studies. ${ }^{20,21}$ Patients are assumed to be already using behavioral therapy techniques in addition to drug 
treatment. Patients with surgically curable causes of incontinence are not included. Patients are prescribed either extended-release tolterodine or controlled-release oxybutynin and are treated for a 12-week (3-month) period. At the end of the 3-month period, patients may be referred to a specialist for further evaluation and treatment, based on their treatment course. The cost associated with the referral, as well as typical diagnostic procedures that are performed by a specialist, is included. Infrequently used second-line treatments ( $<5 \%$ use) are not included. Treatment rates obtained from expert opinion are shown in Table 2.

\section{Resource Consumption}

The following resources are included in the model: medications, physician visits, incontinence pads, physical/behavioral therapy, procedures/tests, treatment of comorbid conditions, and productivity losses (Table 1). Medication costs are calculated using average wholesale prices (AWP). Urinary tract and skin infection costs are based on claims data from California's Medicaid (Medi-Cal) program. All other costs reflect actual payments based on published diagnosisrelated group and physician fee schedules. All costs were inflation-adjusted, if necessary, to reflect 2000 U.S. dollars using the U.S. Bureau of Labor Statistics CPI-U for Medical Care Services.

We assume that the use of incontinence pads, the incidence of comorbid conditions, and the degree of productivity loss will vary based on the extent to which patients required modifications to their initial treatment. For these resources, we assume 3 levels of possible consumption: low, medium, and high. The low and high consumption levels are based on information in the published literature and from expert opinion, while the medium consumption level is calculated as an average of the low and high estimates. The levels are applied to all patients within a specific patient group, as outlined below:

- Continue Monotherapy (no dosing changes)_low consumers

- Add or Switch Therapy (and monotherapy dosing changes) - medium consumers

- Discontinue All OAB Therapy-high consumers

Variable resource rates used in the model are shown in Table 3. Our rationale for assigning these varying levels of resources was based on a retrospective study, ${ }^{29}$ where patients switching $\mathrm{OAB}$ medication during the follow-up period had approximately $12 \%$ higher median per-member-per-month (PMPM) total costs from baseline. In comparison, the group that was maintained on the same OAB therapy had approximately 45\% lower median PMPM total costs from baseline. This suggests that patients who switched $\mathrm{OAB}$ medication in the follow-up period due to treatment failure incurred PMPM total costs 56.6\% higher than subjects who remained on the same OAB medication.

The model does not include patients with $\mathrm{OAB}$ who do not seek professional treatment and, hence, presumably consume few medical resources. Resource consumption characteristics and patient quality of life have not been adequately studied in patients who do not seek treatment for OAB.

Resource utilization associated with key adverse events, such as dry mouth, are reflected in the treatment rates as well as subsequent dose reductions, therapy changes, and discontinuations. Other adverse events are considered to be similar in terms of rates and/or resource utilization between comparators..$^{3-7}$

\section{Drug Dosing}

We assume a starting dose of $4 \mathrm{mg}$ daily for extended-release 
TABLE 2

Treatment Rates-Base-Case Analysis

\begin{tabular}{|c|c|c|}
\hline & $\begin{array}{l}\text { Extended- } \\
\text { release } \\
\text { Tolterodine }\end{array}$ & $\begin{array}{l}\text { Controlled- } \\
\text { release } \\
\text { Oxybutynin }\end{array}$ \\
\hline $\begin{array}{l}\text { Node A } \\
\text { Continue } \\
\text { Change therapy }\end{array}$ & $\begin{array}{l}70 \% \\
30 \%\end{array}$ & $\begin{array}{l}61 \% \\
39 \%\end{array}$ \\
\hline $\begin{array}{l}\text { Node B } \\
\text { Continue } \\
\text { Add therapy }\end{array}$ & $\begin{array}{l}83 \% \\
17 \%\end{array}$ & $\begin{array}{l}83 \% \\
17 \%\end{array}$ \\
\hline $\begin{array}{l}\text { Node C } \\
\text { Switch therapy } \\
\text { Discontinue OAB therapy }\end{array}$ & $\begin{array}{l}80 \% \\
20 \%\end{array}$ & $\begin{array}{l}80 \% \\
20 \%\end{array}$ \\
\hline $\begin{array}{l}\text { Node D } \\
\text { Increase dose } \\
\text { Decrease dose } \\
\text { Same dose }\end{array}$ & $\begin{array}{l}14 \% \\
5 \% \\
81 \%\end{array}$ & $\begin{array}{l}32 \% \\
6 \% \\
62 \%\end{array}$ \\
\hline $\begin{array}{l}\text { Node E } \\
\text { Pharmacologic therapy } \\
\text { Nonpharmacologic therapy }\end{array}$ & $\begin{array}{l}80 \% \\
20 \%\end{array}$ & $\begin{array}{l}83 \% \\
17 \%\end{array}$ \\
\hline $\begin{array}{l}\text { Node F } \\
\text { Pharmacologic therapy } \\
\text { Nonpharmacologic therapy }\end{array}$ & $\begin{array}{l}90 \% \\
10 \%\end{array}$ & $\begin{array}{l}90 \% \\
10 \%\end{array}$ \\
\hline $\begin{array}{l}\text { Node G } \\
\text { Referred to specialist } \\
\text { Lost-to-followup }\end{array}$ & $\begin{array}{l}75 \% \\
25 \%\end{array}$ & $\begin{array}{l}75 \% \\
25 \%\end{array}$ \\
\hline $\begin{array}{l}\text { Node } \mathbf{H} \\
\text { Imipramine } \\
\text { Estrogen } \\
\text { Other drug therapy }\end{array}$ & $\begin{array}{l}38 \% \\
33 \% \\
29 \%\end{array}$ & $\begin{array}{l}38 \% \\
33 \% \\
29 \%\end{array}$ \\
\hline $\begin{array}{l}\text { Node I } \\
\text { Biofeedback } \\
\text { Electrical stimulation } \\
\text { Other nonpharmacologic therapy }\end{array}$ & $\begin{array}{c}72 \% \\
23 \% \\
5 \%\end{array}$ & $\begin{array}{c}72 \% \\
23 \% \\
5 \%\end{array}$ \\
\hline $\begin{array}{l}\text { Node J } \\
\text { Imipramine } \\
\text { Estrogen } \\
\text { Controlled-release oxybutynin } \\
\text { or extended-release tolterodine } \\
\text { Other drug therapy } \\
\end{array}$ & $\begin{array}{c}18 \% \\
8 \% \\
71 \% \\
3 \%\end{array}$ & $\begin{array}{c}17 \% \\
7 \% \\
74 \% \\
2 \%\end{array}$ \\
\hline $\begin{array}{l}\text { Node K } \\
\text { Biofeedback } \\
\text { Electrical stimulation } \\
\text { Other nonpharmacologic therapy }\end{array}$ & $\begin{array}{c}58 \% \\
37 \% \\
5 \%\end{array}$ & $\begin{array}{c}58 \% \\
37 \% \\
5 \%\end{array}$ \\
\hline
\end{tabular}

tolterodine and $5 \mathrm{mg}$ daily for controlled-release oxybutynin with an increase to $10 \mathrm{mg}$ after one week (package insert). ${ }^{30}$ We assume that patients requiring a dosage increase at 6 weeks will be prescribed extended-release tolterodine $6 \mathrm{mg}$ daily or controlled-release oxybutynin $15 \mathrm{mg}$ daily. Patients requiring a dosage decrease will be prescribed extended-release tolterodine $2 \mathrm{mg}$ daily or controlled-release oxybutynin $5 \mathrm{mg}$ daily. Patients receiving imipramine received $50 \mathrm{mg} 3$ times daily, and patients receiving estrogen received estrogen cream 2 gm every other day. For patients receiving "Other Drug Therapy," we developed a representative cost based on commonly prescribed doses of flavoxate, dicyclomine, and hyoscyamine.

\section{Office Visits}

Our model assumes an initial consultation with a PCP when beginning drug treatment. Follow-up visits occur at 6 weeks and 3 months following initiation of drug treatment. We assume that all patients in the "Discontinue OAB Treatment" group have one PCP physician visit at 6 weeks, and that by 3 months, these patients are either referred to a specialist or discontinue treatment altogether. We assume that all patients seeking treatment are established patients rather than new patients, and they are assigned CPT-4 codes of 99213 or 99214 for the office visits, depending upon whether a change in treatment was required. For urologist-referral visits, a CPT-4 code of 99244 was assigned.

\section{Physical/Behavioral Therapy}

We assume that all patients enter the model already receiving behavioral therapy and that drug therapy can be used in combination. Additional nonpharmacologic therapies include biofeedback and electrical stimulation.

\section{Procedures/Tests}

We assume all patients have had a urinalysis before entering the model and beginning drug treatment. We assume that patients who are referred to urologists will have another urinalysis. We assume that some patients who add or switch therapy will receive another urinalysis during their next office visit and that patients who continue to be managed by their PCP will have no further monitoring or tests. Patients referred to urologists will have additional procedures, as shown in Table 4.

\section{Incontinence Pad Usage}

For the proportion of $\mathrm{OAB}$ patients with urge incontinence $(37 \%),{ }^{5}$ we assume they use an average of 4 pads per day at baseline. After treatment, low resource consumers require an average of 2 pads per day, the medium group will use 3 pads per day, and high resource consumers continue to use 4 pads per day.

\section{Comorbid Conditions}

We included the cost of treating urinary tract infections (UTIs), skin infections, fractures, and depression as $\mathrm{OAB}$ patients are at greater risk for all of these comorbid conditions., ${ }^{31,32}$ The rates of these events were determined from published literature. ${ }^{26,31,33}$ The frequency of treatment for these events vary based on treatment characteristics, such that low resource consumers experience fewer events and require the fewest treatment services, while high resource consumers experience more frequent events and require more treatment services. 


\section{Productivity and Work Loss}

Employer costs of OAB include sick leave, short-term disability, worker's compensation, pharmacy costs, medical insurance costs, and lost productivity. A study of employer costs showed an annual cost of $\$ 4,020$ for $\mathrm{OAB}$ patients compared to $\$ 2,633$ in the non$\mathrm{OAB}$ population. ${ }^{34}$ We used the incremental difference in employer costs between the $\mathrm{OAB}$ and non-OAB populations to estimate 3-month productivity losses for each resource group. We conservatively assumed that patients in the low resource group experienced no productivity losses over 3 months.

\section{Referral Rates}

We estimated, using expert opinion, the referral rates to a specialist and the percentage of patients who would be lost to follow-up at 3 months. The cost of a referral includes an office visit to a specialist as well as the cost of procedures (weighted by the percentage of patients expected to receive each procedure) that are likely to be performed at the first visit. Referral rates are shown in Table 5.

\section{Base-Case Analysis and Sensitivity Analysis}

A base-case analysis was run to determine the probable average 3-month treatment cost per patient initiating therapy with either extended-release tolterodine or controlled-release oxybutynin. We performed sensitivity analyses on key parameters of cost, resource utilization, and treatment rate, using $\mathrm{a} \pm 10 \%$ and $25 \%$ range around key variables. The variables included firstline drug costs, non-first-line drug costs, all costs, resource utilization, all treatment rates, and treatment rates at specific nodes. Wider cost ranges using retail pharmacy prices were applied to the highly variable cost of incontinence pads. Tornado diagrams (Figures 2 and 3) were used to show the impact of several key variables. A tornado diagram visually displays the results of single-factor sensitivity analyses. The uncertainty in the parameter associated with the widest bar has the maximum impact on the result, with each successive lower bar having a lesser impact.

\section{Results}

\section{Base-Case Analysis}

The base-case analysis showed that an average patient initiating therapy with extended-release tolterodine has 3-month treatment costs of $\$ 1,207$ compared to $\$ 1,283$ for controlled-release oxybutynin, a $6.3 \%$ difference. First-line $\mathrm{OAB}$ drug costs account for $19 \%$ and $15 \%$ of total costs for extended-release tolterodine and controlled-release oxybutynin, respectively. Results for the base-case analysis are shown in Table 6.

The rate at which an average patient will continue monotherapy with extended-release tolterodine is higher compared to controlled-release oxybutynin, $58.1 \%$ versus $50.6 \%$, respectively. At the same time, the average probable costs for a patient continuing monotherapy was $6.4 \%$ lower with extend-

\begin{tabular}{lccc}
\hline \multicolumn{1}{c}{ TABLE 3 } & Model Rates for Variable Resources \\
\hline Resource & Low & Medium & High \\
\hline $\begin{array}{l}\text { Incontinence pads } \\
\text { (per day) }\end{array}$ & 2 pads & 3 pads & 4 pads \\
\hline $\begin{array}{l}\text { Comorbid Conditions } \\
\text { UTIs (22.5\% } \\
\text { of population }\end{array}$ & 1.9 services & 2.6 services & 3.3 services \\
\hline $\begin{array}{l}\text { Skin infections } \\
(8 \% \text { of population) }\end{array}$ & 0.65 services & 1.15 services & 1.65 services \\
\hline Depression $^{32}$ & 0.17 & 0.385 & 0.60 \\
\hline Fractures $^{13,33}$ & 0.00208 & 0.00235 & 0.00263 \\
\hline
\end{tabular}

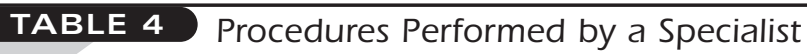

\begin{tabular}{l|c}
\hline Procedure & \% of Patients Receiving Procedure \\
\hline Cystoscopy & $69 \%$ \\
\hline Complex cystometrogram/ & $75 \%$ \\
Pressure flow urodynamics & $30 \%$ \\
\hline Urine flowmetry & $8 \%$ \\
\hline Urethral pressure profile & $8 \%$ \\
\hline Cystogram (VCUG) & $53 \%$ \\
\hline Urine cytology & $78 \%$ \\
\hline Post-void residual & $100 \%$ \\
\hline Urinalysis &
\end{tabular}

\section{TABLE $5 \longdiv { \text { Referral Rates } }$}

\begin{tabular}{l|c}
\hline Node & \% of Patients Referred \\
\hline Node D Pathways & $26 \%$ \\
\hline Node G Pathways & $75 \%$ \\
\hline Node H Pathways & $64 \%$ \\
\hline Node I Pathways & $61 \%$ \\
\hline Node J Pathways & $51 \%$ \\
\hline Node K Pathways & $51 \%$ \\
\hline
\end{tabular}

ed-release tolterodine (\$963 to $\$ 1,041$ ). Conversely, a controlled-release oxybutynin patient was $7.2 \%$ more likely to switch therapy, although costs were only slightly higher compared with extended-release tolterodine $(\$ 1,491$ to $\$ 1,482)$. The other post-first-line drug therapy options (add therapy, and discontinue $\mathrm{OAB}$ therapy) all showed less than a $2 \%$ difference in probable cost per patient between the comparators.

Compared to extended-release tolterodine, the controlledrelease oxybutynin results show that a larger percentage of the total costs come from not continuing first-line therapy. On average, more than $36 \%$ of costs for a patient will come from switch- 
A Pharmacoeconomic Model Comparing Two Long-Acting Treatments for Overactive Bladder

TABLE 6 Model Analysis Results

\begin{tabular}{|c|c|c|c|}
\hline & $\begin{array}{l}\text { Extended-release } \\
\text { Tolterodine }\end{array}$ & $\begin{array}{l}\text { Controlled-release } \\
\text { Oxybutynin }\end{array}$ & Difference* $(\%)$ \\
\hline Total Probable Cost per Patient & $\$ 1,206.86$ & $\$ 1,283.20$ & $\$ 76.34(6.3 \%)$ \\
\hline \multicolumn{4}{|c|}{ Components of Total Probable Cost per Patient-\% of costs } \\
\hline Continue monotherapy & $46.4 \%$ & $41.0 \%$ & $-5.4 \%$ \\
\hline Add therapy & $16.4 \%$ & $13.3 \%$ & $-3.1 \%$ \\
\hline Switch therapy & $29.5 \%$ & $36.3 \%$ & $6.8 \%$ \\
\hline TOTAL & $100.0 \%$ & $100.0 \%$ & $0.0 \%$ \\
\hline \multicolumn{4}{|c|}{$\begin{array}{l}\text { Total Probable Cost per Patient with Each Treatment Option } \\
\text { (\% = average rate of treatment) }\end{array}$} \\
\hline Continue monotherapy & $\$ 963.37(58.1 \%)$ & $\$ 1,040.51(50.6 \%)$ & $\$ 77.14(-7.5 \%)$ \\
\hline Add therapy & $\$ 1,667.73(11.9 \%)$ & $\$ 1,649.34(10.4 \%)$ & $-\$ 18.39(-1.5 \%)$ \\
\hline
\end{tabular}

ing therapy, and more than $9 \%$ of costs come from discontinuing $\mathrm{OAB}$ therapy. In contrast, less than $30 \%$ of extended-release tolterodine costs come from switching therapy, and less than $8 \%$ of costs come from discontinuing $\mathrm{OAB}$ therapy.

\section{Sensitivity Analyses}

Results from sensitivity analyses are shown in Table 7. These results are graphically depicted as tornado diagrams in Figures 2 and 3 .

\section{Costs}

Sensitivity analyses on costs were relatively stable. No cost parameter change resulted in an overall cost advantage for controlled-release oxybutynin. The magnitude of extended-release tolterodine's cost advantage was most affected by changes in all other costs, i.e., costs other than first-line drug costs (where a $25 \%$ increase/decrease in costs resulted in a 34\% increase/ decrease in the cost advantage). Changes in either drug costs or all costs had less impact on the magnitude of extended-release tolterodine's cost advantage.

Break-even costs for the OAB first-line drugs were also calculated. The cost of extended-release tolterodine can be increased up to $34 \%$ above the base case before equaling controlled-release oxybutynin. Conversely, the cost of controlledrelease oxybutynin would have to be reduced by $39 \%$ before achieving cost parity.

\section{Resource Utilization}

A sensitivity analysis was also performed on the key assumption that variations in resource utilization depend on the effective- ness of the drug therapy. If no difference in resource utilization is assumed, and patients are assigned low, medium, or high resource utilization, then any cost differential between the 2 therapies disappears, with controlled-release oxybutynin having a slight (less than 1\%) cost advantage over extended-release tolterodine. Overall cost differences between the 2 treatments are, therefore, highly dependent on the assumption that resource consumption is related to the patterns of treatment.

\section{Treatment Rates}

Sensitivity analysis on treatment rates shows they are key parameters driving the results of the model. Several scenarios were examined, including (1) reversing the treatment rates for extended-release tolterodine and controlled-release oxybutynin, (2) assigning both treatment groups the extended-release tolterodine treatment rates, (3) assigning both groups the controlledrelease oxybutynin treatment rates, and (4) varying the rates at key nodes. The first scenario, which reversed the treatment rates for the 2 products, showed that costs for patients receiving controlled-release oxybutynin would be $10 \%$ less than for patients receiving extended-release tolterodine, as one would expect. The second scenario, where treatment rates are equal, resulted in similar costs between the 2 products, with controlled-release oxybutynin being approximately $1 \%$ less costly.

Varying the probabilities at nodes $\mathrm{A}$ and $\mathrm{D}$ also demonstrated some sensitivity. At node A, if the rate of continuing extendedrelease tolterodine was decreased by about 20 percentage points, or if the rate of continuing controlled-release oxybutynin was increased 20 percentage points, the overall costs would be equal. It was also found that if the rates of dose increases were equal 
A Pharmacoeconomic Model Comparing Two Long-Acting Treatments for Overactive Bladder

\section{TABLE 7 Sensitivity Analysis Results (Bold Indicates Base-Case Costs)}

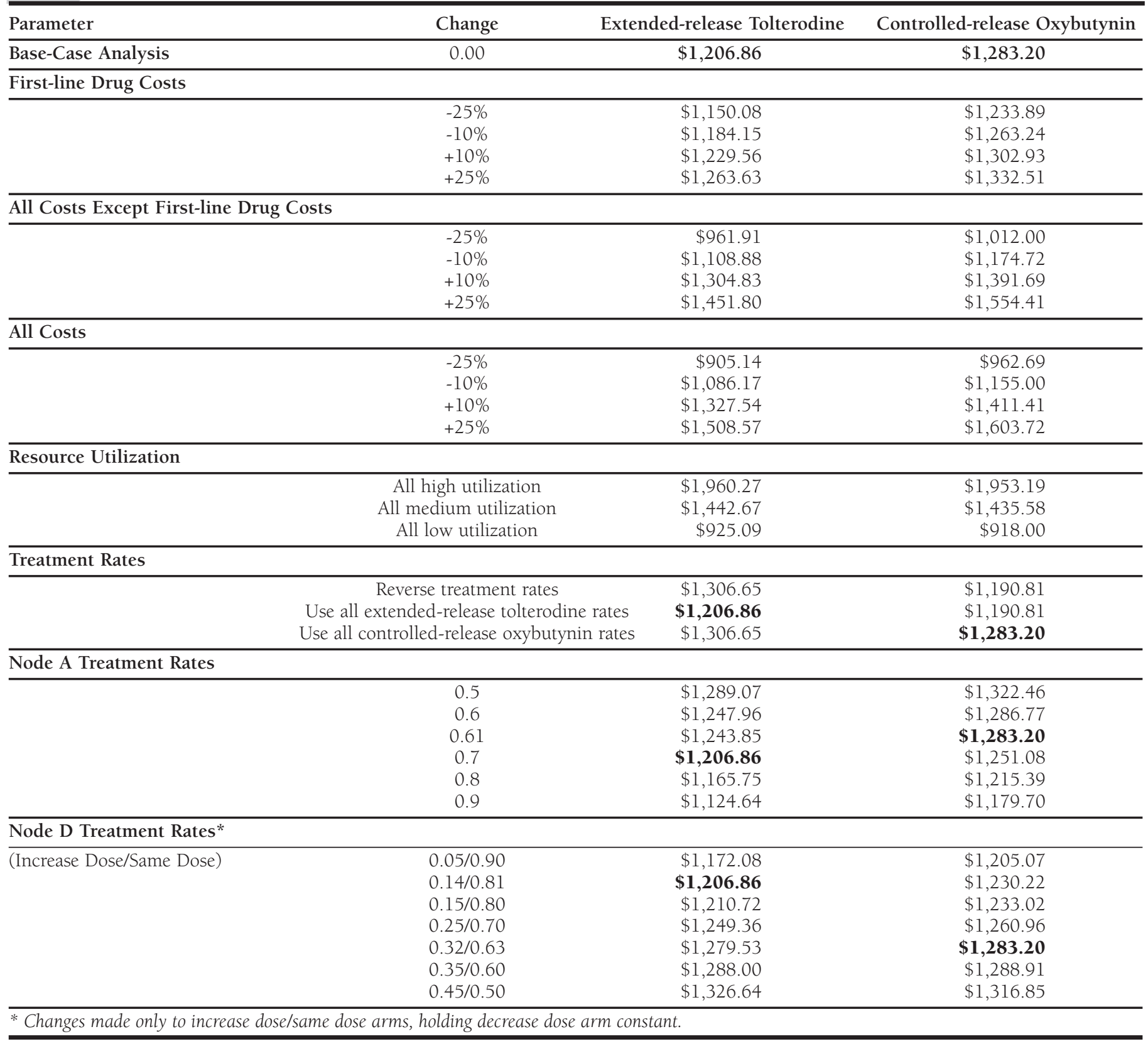

(node D), the 2 drugs would be nearly cost-equivalent.

\section{Discussion}

The model results suggest that extended-release tolterodine yields a small cost advantage over controlled-release oxybutynin when used as a first-line therapy in the PCP setting. Extendedrelease tolterodine patients would be expected to incur fewer costs related to resources such as physician visits and referrals, comorbidities, and productivity loss. Although most patients continued monotherapy, more patients taking extended-release tolterodine continued without dosage changes, and more patients on controlled-release oxybutynin incurred dose increases. Thus, in this model, fewer resources were consumed by extended-release tolterodine patients.

While sensitivity analysis showed that the results are stable for a range of costs, both drug and nondrug, the model did show some degree of sensitivity to assumptions related to resource utilization and treatment rates. We assumed that 

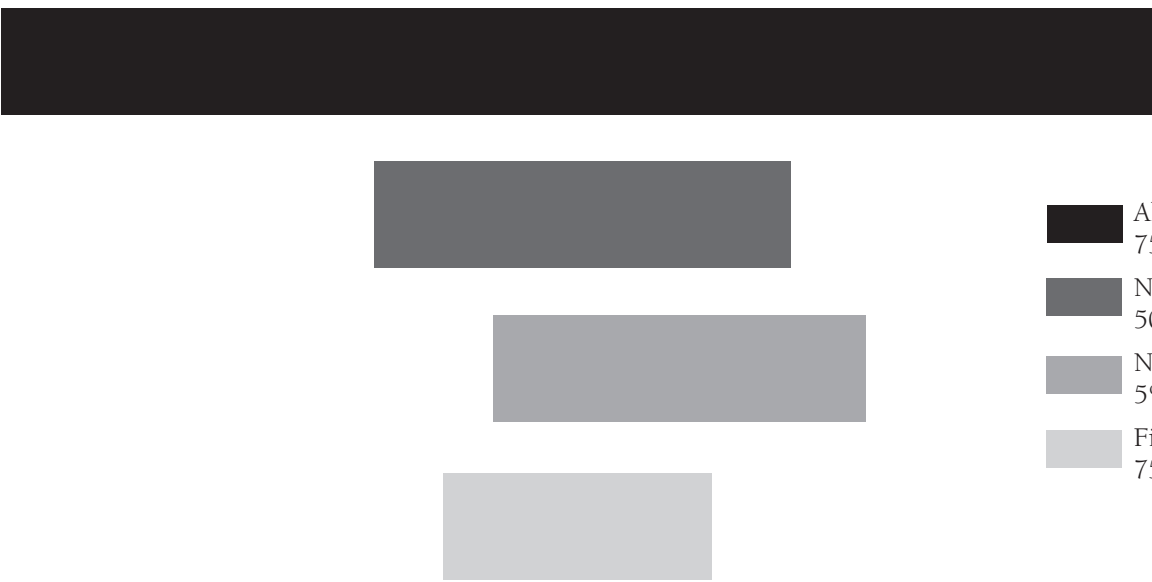

\begin{tabular}{cccc|c|c|c|c|c|c|}
900 & 1,000 & 1,100 & 1,200 & 1,300 & 1,400 & 1,500 \\
\hline
\end{tabular}

resource consumption varied depending on treatment effectiveness. If we assume resource utilization is unrelated, overall treatment costs are virtually identical between the 2 treatments. Key treatment rates were those showing that extended-release tolterodine patients would continue on first-line monotherapy without dosage changes at a higher rate than controlled-release oxybutynin patients. If these rates are made equal or reversed, the cost advantage for extended-release tolterodine disappears. However, discussions with clinical experts, along with existing retrospective studies, ${ }^{10,35}$ suggest higher continuation rates, and greater persistence can be expected for extended-release tolterodine as compared to controlled-release oxybutynin.

The model does not address a few important issues. Information regarding resources consumed by patients who do not seek treatment for $\mathrm{OAB}$ is lacking; therefore, these patients were excluded. We did not include other possible treatments for $\mathrm{OAB}$ or the effectiveness of nonpharmacologic treatments, whether alone or in combination with drug therapy, as these are not well-documented. The quality-of-life (QOL) impact of OAB has been studied, but insufficient information is available regarding patient utilities to incorporate quality of life into the model. The long-term impact of drug treatment is unknown, and was not considered in the model.

Drug compliance is an important issue for $\mathrm{OAB}$ treatment; however, in our model, compliance was not addressed directly. Since the model was conducted from a payer perspective, different compliance rates do not impact the cost calculations in the model as the amount of drug purchased would be the same regardless of compliance. Noncompliance leading to changes in therapy or discontinuation of treatment was considered in developing treatment rate estimates. The possible effect of differing compliance rates on efficacy among the comparators is not known.
While clinical trials of drugs for $\mathrm{OAB}$ have most often focused on reducing the number of incontinence episodes as the primary efficacy endpoint, other variables are also relevant, such as reduced micturitions, smaller urine volume, reduced urgency, minimal side effects, ability to tolerate and remain on medication, and nighttime incontinence and urgency, to name a few. Quality of life, social issues, coping skills, nonpharmacologic interventions, and the patient's motivation to comply with those interventions all play a role in an $\mathrm{OAB}$ patient's treatment. This complexity makes it difficult to comprehensively model the disease and its treatment while taking these aspects into consideration.

Many variables contribute to whether or not a particular treatment is effective. The symptoms of $\mathrm{OAB}$ - which include not only urge incontinence but also urgency and/or frequency-have a significant, negative impact on patient QOL, and the goal of treatment is to reduce symptoms and improve QOL. Also, a patient must remain on therapy for it to have the chance to be effective. Therefore, products that are better tolerated are more likely to produce a positive outcome. A therapy that reduces symptoms, improves QOL, and is well-tolerated should reduce the need for other medical resources that are used to treat the disease.

\section{Conclusion}

The results from this analysis suggest that for patients with $\mathrm{OAB}$ who are initiating long-acting pharmacologic therapy in the primary care setting, treatment with extended-release tolterodine is slightly less costly than treatment with controlled-release oxybutynin. With recent studies showing better persistency and tolerability for extended-release tolterodine compared to controlled-release oxybutynin, further clinical and economic studies need to incorporate the complex interaction of effectiveness, 

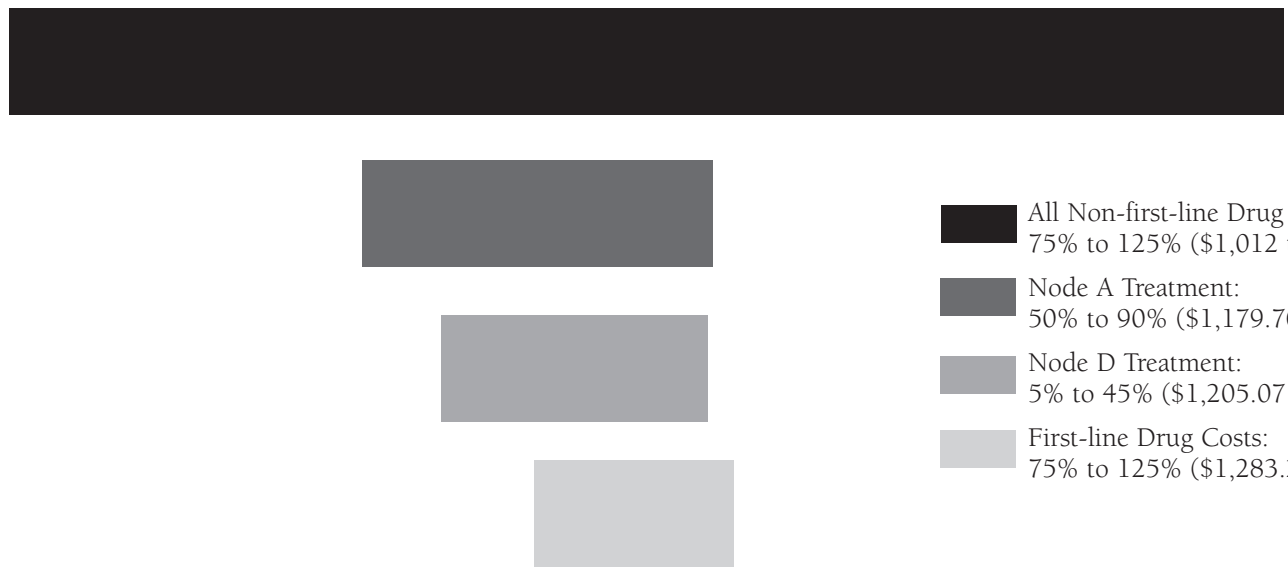

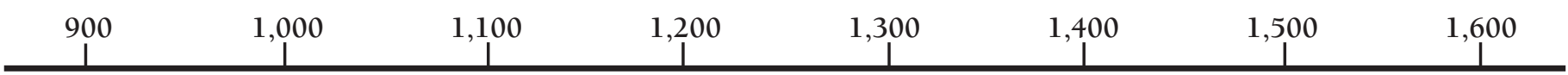

tolerability, persistence, and QOL changes and the resulting cost offsets. These efforts will add to the base knowledge gained from our analysis and help decision makers further distinguish between the 2 drugs.

\section{DISCLOSURES}

Funding for this research was provided by Pharmacia Corporation and was obtained by authors Les Noe, Russell Becker, and Todd Williamson. Noe is a paid consultant for Pharmacia; Becker and author Donny Chen received grants from Pharmacia (makers of tolterodine); and Williamson is an employee of Pharmacia. Noe served as principal author of the study. Study concept and design, analysis and interpretation of data, and critical revision were contributed by Noe, Becker, Chen, and Williamson. Drafting of the manuscript was primarily the work of Noe. Administrative, technical and/or material support was provided by Noe, Chen, and Becker.

\section{ACKNOWLEDGMENTS}

The authors wish to thank Eric Rovner, MD, of the University of Pennsylvania; David Chaikin, MD, of Morristown Urology (New Jersey); Stuart Diamond, MD, of Jefferson Medical College (New Jersey); and David Ginsberg, MD, of the University of Southern California for participating in the development of this analysis.

\section{REFERENCES}

1. Hu T, Wagner T, Bentkover J, LeBlanc K, et al. on behalf of the NOBLE Program Research Team. Economic costs of overactive bladder (abstract). Accepted for presentation at the 2nd International Consultation on Incontinence; July 1-3, 2001; Paris, France.

2. Zhou Z, Jensen $G$. Insurance claims costs for overactive bladder disorder. Drug Ben Trends. 2001;13(4):45-58.

3. Abrams P, Freeman R, Anderström C, et al. Tolterodine, a new antimuscarinic agent: As effective but better tolerated than oxybutynin in patients with an overactive bladder. Br J Urol. 1998;81:801-10.

4. Appell R. Clinical efficacy and safety of tolterodine in the treatment of overactive bladder: A pooled analysis. Urology. 1997;50(suppl 6A):S90-S96.

5. Drutz HP, Appell RA, Gleason D, Klimberg I, Radomski S. Clinical efficacy and safety of tolterodine compared to oxybutynin and placebo in patients with overactive bladder. Int Urogynecol J. 1999;10:283-89.

6. Chancellor M, Freedman S, Mitcheson HD, Antoci J, Primus G, Wein A. Tolterodine, an effective and well-tolerated treatment for urge incontinence and other overactive bladder symptoms. Clin Drug Invest. 2000;19:83-91.

7. Millard R, Tuttle J, Moore K, Susset J, et al. Clinical efficacy and safety of tolterodine compared to placebo in detrusor overactivity. J Urol. 1999;161:1551-55

8. Kelleher CJ, Cardozo LD, Khukkar V, et al. A medium term analysis of the subjective efficacy of treatment for women with detrusor instability and low bladder compliance. Br J Obstet Gynaecol. 1997;104:988-93.

9. Lawrence M, Guay DR, Benson SR, Anderson MJ. Immediate-release oxybutynin versus tolterodine in detrusor overactivity: a population analysis. Pharmacotherapy. 2000;20:470-75.

10. Zhou Z, Barr CE, Torigoe Y, Williamson TE. Persistence of therapy with drugs for overactive bladder [abstract]. Value in Health. 2001;4:162-63.

11. Wein AJ, Abrams P, Appell R, Drutz HP. Tolterodine is effective and well tolerated during long-term use in patients with overactive bladder [abstract] J Urol. 1999;161:35.

12. Tucker B, Colli E, Susset J. Patient compliance to treatment of overactive bladder with tolterodine vs. oxybutynin. Paper presented at: International Continence Society 29th Annual Meeting; August 21-26, 1999; Denver, CO.

13. Juzba M, White TJ, Chang EY. Prevalence and cost analysis of overactive bladder in a managed care organization. [abstract]. J Managed Care Pharm. 2001;7(5):365.

14. Taira DA, Davis J, Kessel B, Brizzolara S. Comparing treatment patterns, patient compliance, and economic outcomes of women with overactive bladder. Report to the Pharmacia Corporation; April 2001.

15. Hall JA, Nelson MA, Meyer JW, Williamson T, Wagner S. Costs and resources associated with the treatment of overactive bladder using retrospective medical care claims data. Managed Care Interface. 2001;14(8):69-75.

16. Pashos CL, Grossman M, Bull S. The impact of pharmacotherapy on overactive bladder symptom improvement and resource utilization [abstract]. Value in Health. 2001;4:163-64.

17. Gleason DG, Susset J, White C, et al. Evaluation of a new once-daily formulation of oxybutynin for the treatment of urinary urge incontinence. Urology. 1999;54:420-23. 
18. Anderson RU, Mobley D, Blank B, et al. Once-daily controlled versus immediate-release oxybutynin chloride for urge urinary incontinence. J Urol. 1999;281:1809-12

19. Versi E, Appell R, Mobley D, Patton W, Saltzstein D. Ditropan XL Study Group. Dry mouth with conventional and controlled-release oxybutynin in urinary incontinence. Obstet Gynecol. 2000;95:718-21.

20. Appell RA, Sand P, Dmochowski R, et al. for the OBJECT Study Group. Prospective randomized controlled trial of extended-release oxybutynin chloride and tolterodine tartrate in the treatment of overactive bladder: results of the OBJECT study. Mayo Clin Proc. 2001;76:358-63.

21. van Kerrebroeck P, Kreder K, Jonas U, Zinner N, Wein A on behalf of the Tolterodine Study Group. Tolterodine once-daily: superior efficacy and tolerability in the treatment of the overactive bladder. Urology. 2001;57:414-21.

22. Chapple CR. Tolterodine once-daily: selectivity for the bladder over-effects on salivation compared to Ditropan XL (abstract). J Urol. June 2001;165 (5 suppl):S253.

23. Hu T, Wagner TH. Economic considerations in overactive bladder. Am J Managed Care. 2000;6(11 suppl):S591-S598.

24. Williamson TE, Smeeding JE, Davidson TG. Overactive bladder: the hidden economic story. Submitted for publication to Amer J Health-Syst Pharm. July 2002

25. Johannesson M, O'Conner RM, Kobelt-Nguyen G, Mattiasson A.

Willingness to pay for reduced incontinence symptoms. Br J Urol. 1997;80:557-62

26. Kobelt G, Jönsson L, Mattiasson A. Cost-effectiveness of new treatments for overactive bladder: The example of tolterodine, a new muscarinic agent: A Markov model. Neurourol Urodynam. 1998;17:599-611.

27. Arikian SR, Casciano J, Doyle JJ, Tarride JE, Casciano RN. A pharmacoeconomic evaluation of 2 new products for the treatment of overactive bladder. Managed Care Interface. 2000 Feb;13(2):88-94.
28. Becker RV, Noe LL, Trotter JP, Williamson TE. A cost-effectiveness comparison of extended-release tolterodine (Detrol LA) versus controlled-release oxybutynin (Ditropan XL) (abstract). Presented at: 80th Annual Meeting of the South Central Section of the American Urological Association; September 12, 2001; Austin, TX

29. Nilvebrant L, Gillberg PG, Sparf B. Antimuscarinic potency and bladder selectivity of PNU-200577, a major metabolite of tolterodine. Pharmacol Toxicol. 1997;81:169-72

30. 2001 Mosby's GenRx. St. Louis, MO: Mosby, Inc; 2001.

31. Brown JS, McGhan WF, Chokroverty S. Comorbidities associated with overactive bladder. Am J Managed Care. 2000(suppl);6:S576-S579.

32. Zorn BH, Montgomery H, Pieper K, Gray M, Steers WD. Urinary incontinence and depression. J Urol. 1999;282:82-84.

33. Brown JS, Vittinghoff E, Wyman JF, et al. Urinary incontinence: Does it increase risk for falls and fractures? J Am Geriatr Soc. 2000;48:721-25.

34. Data on file, Pharmacia Corporation, Peapack, NJ.

35. Zhou Z, Barr CE, Torigoe Y, Williamson TE. Evidence of disease progression in adult patients with an overactive bladder (OAB) [abstract]. Value in Health. 2001;4:162

36. U.S. Department of Health and Human Services, Centers for Medicare and Medicaid Services Web site. Available at:

http://cms.hhs.gov/providers/pufdownload/carr.puf.asp. Physician Fee Schedule Payment Amount National/Carrier, 2001.

37. 2001 Drug Topics Red Book. Montvale, NJ: Medical Economics Company, Inc.; 2001

38. DRG Guidebook 2000. Reston, VA: St. Anthony Publishing, 1999

39. U.S. Bureau of Labor Statistics Web site. Available at:

http://www.bls.gov/cpi. CPI-U for Medical Care Services, 2001. 